\title{
Polonês ou polaco: um caso de variação lexical na língua portuguesa
}

\section{Polonês or polaco (Polish): a Case of Lexical Variation in the Portuguese Language}

\author{
Bruno Maroneze [brunomaroneze@ufgd.edu.br] \\ Universidade Federal da Grande Dourados (UFGD), Dourados, Brasil \\ Letícia Tranquile da Silva [leticiatranquiledasilva@gmail.com] \\ Universidade Federal da Grande Dourados (UFGD), Dourados, Brasil
}

\begin{abstract}
RESUMO
A língua portuguesa dispõe de duas formas para designar o indivíduo originário da Polônia: polaco (forma preferida em Portugal) e polonês (forma preferida no Brasil), ambas com longa tradição na língua e com cognatos em outras línguas românicas. Neste trabalho, buscamos explanar as razões que levaram ao abandono da forma polaco no Brasil. Identificamos que polaco adquiriu quatro acepções, três delas pejorativas, em decorrência de fatos históricos ocorridos no Brasil ao longo dos séculos XIX e XX: "prostituta" (na forma feminina polaca), "comerciante", "a Constituição de 1937" e "pessoa loira e/ou de pele muito branca". Recentemente, tem ocorrido um movimento pela revitalização da forma polaco como gentílico, buscando eliminar preconceitos étnicos. Assim, fica evidente a relação intrínseca entre léxico e fatos histórico-sociais.
\end{abstract}

\section{Palavras-Chave}

Polaco; polonês; Lexicologia diacrônica; relações entre léxico e história

\begin{abstract}
The Portuguese language has two forms to refer to the person from Poland: polaco (preferred in Portugal) and polonês (preferred in Brazil), both with a long tradition in the language and with cognates in other Romance languages. In this work, we seek to explain the reasons that led to the abandonment of the form polaco in Brazil. We identified that polaco acquired four meanings, three of them pejorative, due to historical facts that occurred in Brazil during the 19th and 20th centuries: "prostitute" (in the feminine form polaca), "trader, salesman", "the Constitution of 1937" and "blond-haired and/or white-skinned person". Recently, there has been a movement to revitalize the form polaco as a gentilic, in order to eliminate ethnic prejudice. Thus, the intrinsic relationship between lexicon and historical-social facts becomes evident.
\end{abstract}

\section{KEYWORDS}

Polaco; polonês; Polish; Pole; Diachronic Lexicology; relationship between lexicon and history 


\section{Introdução ${ }^{1}$}

Na língua portuguesa, existem principalmente duas unidades lexicais para o gentílico que designa o cidadão oriundo da Polônia: polonês (forma preferida no Brasil) e polaco (forma preferida em Portugal). Buscando entender as razões pelas quais cada uma das duas variedades da língua preferiu adotar uma forma diferente, identificamos que a forma polaco, no Brasil, sofreu diversas alterações de sentido, adquirindo acepções pejorativas, em decorrência de fatos históricos relacionados à imigração polonesa no Brasil.

Sobre isso, a seguinte citação de Napoleão Mendes de Almeida (1981: 238-239) é bastante reveladora:

Polonês, Polaco - Na festiva hora do recreio da escola e na versatilidade de estudante que não se preocupa com os anos vindouros, fomos admoestado ${ }^{2}$ por uma colega, natural da Polônia, de que não o devíamos chamar polaco e sim polonês, e este argumento empregou: polaco usa-se pejorativamente para designar os nascidos em territórios antes pertencentes à Rússia.

Interrogado mais tarde sobre o assunto, fomos entender-nos, para resposta mais segura, com o vice-cônsul da Polônia em São Paulo. Passando por cima de Cândido de Figueiredo, que diz ser "polonês" galicismo, e desrespeitando o aguilhoador escrúpulo de Carlos Góis, que manda usar "polônio" (forma usada por Camões) ou "polaco" (forma popular e moderna), fomos procurar não o filólogo doutrinador, mas o homem senhor do vocábulo. Essa orientação sempre tivemos ao tratar de termos técnicos ou de uso especializado; não nos parece razoável tratar tais palavras a ferro e fogo; nestas pegadas poucas coisas poderiam ser rigorosa e precisamente nomináveis.

Quase idêntico ao do colega de décadas atrás foi o argumento apresentado pelo vice-cônsul, que, também já há tempos, não deixou de emprestar ao vocábulo polaco sentido pejorativo: "O gentílico polaco, não obstante encontrar-se em dicionários portugueses e espanhóis, adquiriu no Brasil principalmente no Rio de Janeiro, sentido pejorativo, tornando-se designativo de agentes de comércio ilícito, exercido quase sempre por judeus, vindos da Polônia, o que nos obrigou a substituir essa palavra por polonês, para distinguir os genuínos habitantes da Polônia. Foi assim que, uma vez restaurada a Polônia e estabelecida sua representação no Brasil, tivemos o cuidado de fazer essa diferenciação, adotando a forma polonês, baseado em formas comuns e usuais, como francês, inglês, holandês e outras."

Dois argumentos obrigam-nos a preferir polonês: um, o atendimento ao sentido de que é usado o vocábulo; outro, amoldar-se perfeitamente aos fatos da língua.

\footnotetext{
1 Nesses tempos de pandemia e isolamento social, o acesso a bibliotecas torna-se dificultado ou impossibilitado. Assim, a consulta a fontes impressas não disponíveis online ficou bastante restrita. A escrita deste artigo não teria sido possível sem a valiosa colaboração de outros pesquisadores, que muito gentilmente fizeram a consulta de obras lexicográficas e outras fontes e nos enviaram. Assim, agradecemos a contribuição de João Henrique Lara Ganança, Roberto Palazzi Ribeiro, Marcelo Módolo e a equipe de bibliotecários do IEB-USP, supervisionada por Daniela Piantola. Os problemas presentes neste artigo, evidentemente, são de nossa inteira responsabilidade.

2 Aqui, como nas demais citações, mantemos a grafia original dos textos, conservando inclusive possíveis erros e gralhas existentes nos textos originais.
} 
A força depreciativa da forma polaco chegou a tal ponto que, além de indicar o não realmente descendente de estirpe polonesa (russos, judeus e outros), passou no Brasil a designar, na forma feminina, meretriz, e da mais refinada; não só: por isso mesmo, polaca veio no Brasil a indicar a constituição arranjada de um momento para outro em novembro de 1937.

Semelhante modificação de significado é comum, sujeita à lei das línguas vivas, em que os termos adquirem sentido diverso do original; é disso exemplo o vocábulo rapariga que, não obstante nenhuma semelhança ter no francês, não pode ser usado no Brasil na acepção com que vive em Portugal.

Almeida consulta até mesmo uma autoridade diplomática, que lhe confirma o sentido pejorativo de polaco, por esta palavra ter designado "agentes de comércio ilícito", em geral judeus poloneses; e menciona ainda a forma feminina polaca, que teria designado "meretriz" e, também, a Constituição brasileira de 1937. Por isso, conclui o autor, a forma preferida no Brasil deve ser, realmente, polonês.

Neste artigo, investigamos mais pormenorizadamente a polissemia de polaco no português brasileiro, buscando identificar em que momentos históricos e com que motivações surgem as suas diversas acepções. Pudemos perceber que a análise minuciosa dessa polissemia levanta pontos importantes sobre as mudanças sociais e a percepção que os falantes da língua portuguesa tiveram e ainda têm sobre o povo polonês. Dessa forma, fica evidente que o léxico se estrutura com base em fatos histórico-culturais, e o seu estudo diacrônico traz evidências importantes para entender a sociedade falante da língua.

Na seção 1, recuperamos a etimologia e as primeiras ocorrências das formas polonês e polaco em português em comparação com outras línguas românicas. Na seção 2, descrevemos quatro acepções da forma polaco no português brasileiro, buscando recuperar os momentos históricos em que surgiram e suas motivações. $\mathrm{Na}$ seção 3, apresentamos brevemente textos recentes que buscam revitalizar o emprego de polaco no Brasil. Por fim, nas considerações finais, trazemos reflexões sobre as relações entre o léxico e a sociedade a partir dos dados que reunimos ao longo do trabalho.

\section{Etimologia e história das formas polonês e polaco}

Ambas as unidades lexicais têm uma tradição de vários séculos na língua portuguesa. Segundo Antônio Geraldo da Cunha (1982), a forma polaco data de 1562, enquanto a forma "polonês" é cerca de um século mais recente, datando de 1656.

Houve também uma terceira forma, o gentílico polônio, datado, segundo Cunha (1982), de 1552. Essa forma é encontrada na célebre obra “Os Lusíadas”, de Luís de Camões, no canto terceiro, décima-primeira estrofe: “... e, na montanha / Hircínia, os marcomanos são polônios” (Camões 1990: 106 - a primeira edição data de 1572). No entanto, essa forma aparentemente caiu em desuso já no século XVIII (conforme se percebe por meio de buscas no portal Google Livros). Cunha (1982) também menciona uma quarta forma, polono, datada de 1566, mas que não aparece em buscas no portal Google Livros (exceto em compostos, como polono-russo).

A título de ilustração, trazemos exemplos de uso das duas formas em textos de séculos anteriores: 


\section{Polaco:}

o Polaco lhe deu dous golpes, dos quaes lhe levou a cabeça de todo fóra faltando no mar, \& ficando o corpo por hum espaço sem ella: lhe deu hum couce, com que fez que o corpo fosse seguindo o caminho da sua cabeça: \& sabendo os Turcos depois de queymada a Nao, que o Polaco cortára a cabeça ao Turco, nem por isso lhe fizeram mal. (Cabreyra 1636: 16)

\section{Polonês (na grafia polonezes):}

Começáraõ a fazer gente em Choczim, Praça que os Turcos dominaõ na fronteyra de Polonia, cõcorrendo a servillos, naõ só muytos Hungaros, ou levados do interesse, ou inclinados ao seu partido; mas muytos Soldados Polonezes, que despedidos das tropas q’ se reformáraõ, depois de ajustadas as perturbaçoens, que tanto tempo commodáraõ aquelle Reyno, sahiraõ a continuar a vida militar em parcialidade igualmente injusta; (Mascarenhas 1717: 4)

Ambas as formas no mesmo trecho:

Esta tremenda derrota não desanimou ao patriotismo da Polonia, por que a perda da sua nacionalidade lhe dava coragem para novos empenhos, e esperavam os polacos obtel-a pela protecção de Napoleão I, que via nas legiões polonezas a heroicidade de um povo digno de melhor sorte (Mello Moraes 1877: 9-10)

A forma polaco está etimologicamente relacionada a polak, palavra do idioma polonês, mas pode ter entrado na língua portuguesa por meio do italiano polacco (hipótese de Cunha, 1982) ou por meio do francês polaque (hipótese de Machado, 1967). Já a unidade polonês é formada pela sufixação de -ês (formador de gentílicos) ao topônimo "Polônia"; ou seja, uma formação vernácula, ainda que possa ter sido influenciada por formas semelhantes em outras línguas românicas.

Em relação às demais línguas românicas, com exceção do catalão, encontra-se a mesma variação:

a) Em francês, as formas polaque e polonais são ambas atestadas no Trésor de la Langue Française; polaque é datado de 1512, enquanto polonais é datado de 1442 (sob a grafia Poulenoys)3. Interessantemente, a forma polaque é acompanhada das rubricas fam. (familiar) e péj. (pejorativo);

b) em espanhol, ambas as formas polonés e polaco são atestadas no Diccionario de la Lengua Española. Essa obra não registra datações das palavras;

c) em italiano, o dicionário Treccani registra a forma polonése como sinônimo de polacco, mas com a rubrica ant. (antigo). Também não traz datações;

d) em catalão, o Diccionari.cat registra apenas a forma polonès, sem informar datações;

e) em romeno, no website Dexonline, encontram-se registradas as formas polonez e poleác, esta última com as rubricas învechit (obsoleto, em desuso) e regional.

3 Cunha (1982) afirma ser pouco provável que polonês tenha sido formado a partir da forma francesa polonais, que, segundo ele, teria aparecido apenas no século XVII; no entanto, a informação do Trésor de la Langue Française indica que essa influência pode, sim, ter ocorrido. 
Assim, conclui-se que, com exceção do catalão, as línguas românicas em geral trazem formas equivalentes a polonês e a polaco; de acordo com os dicionários consultados, em italiano a forma equivalente a polonês é antiga, enquanto, em romeno, é a forma equivalente a polaco que está em desuso; em espanhol e francês, ambas as formas são usadas, mas, em francês, polaque é familiar e pejorativo ${ }^{4}$.

\section{A polissemia de polonês e polaco e a estigmatização da forma polaco no Brasil}

No português brasileiro, a unidade lexical polaco é polissêmica e, muitas vezes, sentida como pejorativa. Além da acepção de gentílico, podem ser descritas outras três acepções: a) "prostituta, especialmente estrangeira" (na forma feminina polaca); b) "comerciante, mascate"; c) "a Constituição brasileira de 1937"; e d) "pessoa loira e/ou de pele muito clara”. As três primeiras acepções já estão em desuso; a quarta segue sendo encontrada nos dias atuais, ainda que não seja tão frequente. Procuramos rastrear a história de cada uma dessas acepções, que serão descritas a seguir.

\subsection{Polaca como "prostituta, especialmente estrangeira"}

A acepção de polaca como "prostituta, especialmente estrangeira" encontra-se registrada em diversas obras lexicográficas. Essa é a provável causa, segundo o dicionário Houaiss online (Houaiss; Villar, s/d) para a substituição de polaco por polonês no Brasil, conforme se lê no verbete "polaco", na aba "gramática e uso":

no Brasil, do final do sXIX para cá, prevalece o uso de polonês, bem como, nos compostos gentílicos, de polono-, como em polono-russo, antes polaco-russo, prov. porque, no fem., polaca foi us. depreciativamente como 'prostituta'

As motivações históricas dessa acepção são bem conhecidas: a partir do final do século XIX, o Brasil recebeu um contingente significativo de imigrantes do sexo feminino originárias da Europa central e oriental (especialmente, mas não só, da Polônia) que, por variadas razões, passaram a dedicar-se à prostituição (ou, mais provavelmente, eram mulheres traficadas e escravizadas para tornarem-se prostitutas). Uma das primeiras fontes históricas que retrata esse fato é a obra "O Lupanar", de Francisco Ferreira da Rosa (1864-1952), publicado em 189655. Essa obra reúne artigos publicados anteriormente em jornais do Rio de Janeiro, em que são narradas histórias de

4 Não é do escopo deste trabalho investigar o motivo de polaque ser pejorativo em francês; em pesquisas informais, pudemos identificar que o inglês polack e o alemão Polacke também carregam traços pejorativos; hipotetizamos que isso pode ter origem em preconceitos que o povo polonês sofreu na Europa, de forma semelhante ao que ocorreu também no Brasil. Pesquisas posteriores poderão esclarecer melhor essa questão.

5 O tráfico de mulheres da Europa para o Brasil, no entanto, começa mais de uma década antes: Menezes (2017) afirma que datam de cerca de 1870 os primeiros prostíbulos do Rio de Janeiro em que trabalhavam essas mulheres. Bandeira (2014) menciona o ano de 1867 como o ano da chegada do primeiro navio no Rio de Janeiro trazendo mulheres traficadas do Leste europeu. 
mulheres na prostituição e de seus cáftens ${ }^{6}$. No início da obra, o autor menciona as nacionalidades de muitas dessas mulheres: "do sul da Russia, da Polonia, da Turquia, da Austria Hungria, não raro da Grecia e muitas vezes da Roumania” (Ferreira da Rosa, 1896: 10-11). Os cáftens eram, segundo Rosa, judeus: "O caften, de ordinario, é um israelita, é um judeu” (Ferreira da Rosa 1896: 13, grifo no original). Também as mulheres são caracterizadas como de origem judaica:

As desgraçadas que sahem da Polonia, da Allemanha, do sul da Russia, da Austria e da Roumania, [...] são em regra geral judias de baixa camada social, camponias ou filhas de pequenas cidades [...] (Ferreira da Rosa 1896: 194)

Isso também pode ser confirmado pelos nomes de duas mulheres polonesas, claramente nomes de origem judaica: Sarah Rochentall (mencionada à p. 139 da obra) e Anna Rubinstein (mencionada à p. 141).

A obra de Ferreira da Rosa é extremamente preconceituosa tanto em relação às mulheres na prostituição como em relação aos cáftens judeus, de modo que deve ser lida com cautela em suas conclusões; mas é, sem dúvida, uma fonte valiosa para entender a história da prostituição no Rio de Janeiro e no Brasil. No entanto, nessa obra, a palavra polaca não é usada ainda como sinônimo de "prostituta", mas apenas se refere à nacionalidade das mulheres.

Sobre a percepção dos brasileiros em relação aos imigrantes da Europa oriental, há uma curiosa e reveladora passagem do romance "As aventuras do Dr. Bogóloff”, de Afonso Henriques de Lima Barreto (1881-1922). O romance foi publicado inicialmente sob a forma de folhetins, em 1912, e só em 1956 foi publicado em forma de livro (na obra "Os Bruzundangas", conforme explica Costa 2015: 91-92). No seguinte trecho do romance, o personagem Bogóloff, imigrante ucraniano, é confundido pela polícia com um cáften:

O homem da polícia marítima pediu-me que eu escrevesse o nome num papel que me apresentou.

Esteve olhando um instante o papel com as letras e, por fim, indagou de repente:

- Qual é a sua profissão?

O intérprete traduziu em francês e eu o atendi:

- Sou professor.

O homem pareceu não se conformar, olhou-me muito e disse à queima-roupa:

— Você não é "cáften"?

Logo percebi o sentido da palavra, fiquei indignado, mas me contive e por minha vez indaguei:

- Por quê?

O homem da polícia explicou muito ingenuamente:

- Estes nomes em “itch", em “off”, em "sky", quase todos são de “cáftens”. Não falha!

Disse-lhe então que não era, nem nunca tinha sido, mas o homem não acreditou nas minhas palavras, e insistiu:

- Se não é "cáften", é anarquista.

Ainda protestei, ainda desfiz-me em explicações, mas o sujeito teimava na singular idéia:

6 Cáften é um brasileirismo que designa o homem que explora a prostituição, sendo em geral proprietário de estabelecimentos de prostituição (bordéis, casas noturnas) e muitas vezes forçando mulheres a se prostituírem. No português brasileiro contemporâneo, a forma cafetão (com adaptação fonética) é usada mais frequentemente. 
— Esses nomes em "itch", em "off”, em "sky", polacos e russos, quando não são de "cáftens", são de anarquistas.

Ainda que a forma polaco seja usada por Lima Barreto apenas com a acepção gentílica, o trecho revela de forma muito clara as percepções que a sociedade do Rio de Janeiro do início do século XX tinha sobre esses imigrantes.

A partir de que momento, exatamente, a palavra polaca passa a significar "prostituta” ainda é incerto. A data mais recuada que encontramos é 1924: trata-se da obra "Vocabulario de Omissões", de Afonso d'Escragnolle Taunay, em que ele reúne cerca de 1.500 palavras "correntes no Brasil, e em Portugal" mas que não foram registradas na terceira edição do dicionário de Cândido de Figueiredo, de 1922. À p. 72, Taunay define polaca como "Prostituta estrangeira de raça slavica". Assim, é possível hipotetizar que, se em 1924 Taunay considerava essa palavra como "corrente”, ela já estaria sendo empregada desde 1910-1920, aproximadamente.

O emprego mais antigo que encontramos numa obra literária está no romance "Jubiabá", de Jorge Amado, publicado pela primeira vez em 1935 (aqui citado em edição de 2008: 268):

Eunice está bêbeda dizendo que já morreu, que todas estão no inferno. A polaca velha se queixa da sua falta de sorte. Na véspera não arranjara homem. Hoje tampouco. Talvez tenha que ir para a ladeira do Tabuão, onde as mulheres cobram mil e quinhentos, fazem tudo, e morrem depois.

Em obra de 1949, o filólogo Arcy Tenório D’Albuquerque afirma que "O feminino polaca tornou-se pejorativa. [...] Polaca passou a sinonimizar com meretriz, com prostituta” (D’Albuquerque 1949: 128-129), mas não afirma quando essa acepção começou a ser usada nem se ainda era usada em 1949.

Possivelmente o primeiro registro dessa acepção num dicionário de língua geral está no dicionário Aulete, em sua primeira edição brasileira, datada de 1958. No verbete polaca, encontra-se, além da acepção da dança de origem polonesa, a acepção "Meretriz estrangeira", acompanhada das rubricas "brasileirismo" e "popular". A partir desse registro no dicionário Aulete, os dicionários posteriores passaram a registrar essa acepção, ora indicando apenas "prostituta" ou "meretriz", como os dicionários Houaiss (Houaiss; Villar, s/d) e Aurélio (Ferreira 2010), ora definindo como a prostituta estrangeira ou de aparência estrangeira, como os dicionários Aulete (já mencionado) e Michaelis ${ }^{7}$ (2021 online). Alguns dicionários mais recentes incluem rubricas como "desusado" (Ferreira, 2010) e "obsoleto" (Houaiss; Villar, s/d), refletindo adequadamente o fato de que essa acepção não é mais corrente. Um dos motivos para o desaparecimento dessa acepção certamente foi o desaparecimento do fato social: o fim do tráfico de mulheres do Leste europeu para o Brasil. Sobre isso, o trabalho de Bandeira (2014) traz dados importantes.

Em primeiro lugar, cabe destacar que o tráfico de mulheres para o Brasil era orquestrado por uma organização criminosa internacional, a Zwi Migdal:

7 Interessantemente, esse dicionário inclui a rubrica "reg. (N.E.)" (regionalismo do Nordeste brasileiro). Em nenhuma outra fonte foi encontrada qualquer indicação de que essa acepção só teria ocorrido no Nordeste; pelo contrário, ela teria surgido no Rio de Janeiro, conforme mencionamos. 
A Zwi Migdal foi uma organização criminosa constituída por pessoas ligadas à comunidade judaica do Leste Europeu que operou ao longo de meados do século XIX(cerca de 1860) até a eclosão da Segunda Guerra Mundial, em 1939. Essa organização dedicou-se especialmente ao tráfico de mulheres destinadas à prostituição, vindas da própria comunidade judaica ou das populações nãojudaicas que viviam nas vilas judaicas da Europa Central. (Bandeira 2014: 31)

A autora também afirma que o auge da prostituição "polaca" no Rio de Janeiro se deu na chamada "Era Vargas":

As chamadas "polacas" [...] ficaram famosas na mitologia urbana carioca do começo do século XX, e sua presença foi marcante na Era Vargas (1930-1945), na região central do Rio, sobretudo na Lapa, região de cultura boêmia já estabelecida. (Bandeira 2014: 32)

Assim, com o fim do tráfico de mulheres (a partir de 1939) e com o declínio dessa forma de prostituição (a partir de 1945), pode-se hipotetizar que a década de 1950 tenha marcado o fim do emprego da forma polaca como sinônimo de "prostituta". Como os dicionários acabam por registrar as palavras e acepções com um “atraso" em relação ao seu emprego, é possível que, por ocasião do registro no dicionário Aulete (1958), essa acepção já estivesse em vias de se tornar obsoleta.

\subsection{Polaco como "comerciante, mascate"}

Aparentemente, no Rio de Janeiro do início do século XX, a palavra polaco foi empregada como sinônimo de "comerciante". Essa acepção é uma das mais obscuras. Não encontramos registro dela em nenhuma obra lexicográfica importante. Talvez seja essa a acepção mencionada, de passagem, pela autoridade diplomática consultada por Almeida (1981), conforme apresentamos na introdução deste artigo ("agentes de comércio ilícito", possivelmente contrabandistas).

Além dessa possível menção por Almeida, essa acepção é também apresentada em duas obras do já citado filólogo Arcy Tenório D’Albuquerque. Inicialmente, em obra de 1942 ("Falsos Brasileirismos"), ao discutir os sentidos da palavra gringo, encontra-se o seguinte trecho:

No Rio, são comuníssimas frases como: “Olha o gringo da prestação", assim como não rareiam, entre o povo, frases semelhantes: “Olha o polaco da prestação". O vocábulo polaco adquiriu um sentido mais amplo, generalizou-se. Como houvessem afluido ao Rio, centenas de judeus da Polônia (asquernasinos), o povo passou a ter em conta de poloneses os demais vendedores a prestações e o vocábulo polaco chegou mesmo a ter sentido de vendedor a prestações.

Também na já citada obra “O Nosso Vocabulário”, de Arcy Tenório D’Albuquerque, de 1949, lemos:

Quando o Rio começou a ser ameaçadoramente invadido por homens desasseiados, de caras estranhas, nariz característico, vendendo a prestações, em sua maioria êles se diziam naturais da Polônia. Eram judeus asquernazins, oriundos do leste da Europa. 
Procedentes da Russia, da Polônia, de Letônia, da Estônia, da Ucrânia, etc., diziam-se naturais da pátria de Paderewsky; em suma, consideravam-se polacos.

Vulgarizou-se a denominação. Dentro em breve, generalizou-se o vocábulo, o seu sentido ampliou-se. Houve um caso de catacrese, esqueceu-se o significado primitivo da palavra: natural da Polônia e o vocábulo entrou a ser empregado como sinônimo de vendedor a prestações.

No Rio, qualquer estrangeiro que venda a prestações, ainda que não seja natural da Polônia, é... polaco.

Em várias cidades brasileiras, já polaco está sendo empregado com o sentido que lhe é atribuido pelos cariocas. (D’Albuquerque 1949: 127-128)

Para não ter sido registrada em dicionários, essa acepção provavelmente existiu durante um período relativamente curto, ou foi restrita a poucas regiões ou classes sociais. É interessante observar que uma acepção semelhante também ocorre no espanhol da Costa Rica e de Cuba: no verbete polaco do Diccionario de la Lengua Española, na oitava acepção, lê-se: "8. m. C. Rica y Cuba. Vendedor ambulante, en particular el que se dedica a vender ropa por las zonas rurales". Pode-se hipotetizar que ambos os usos (em português brasileiro e espanhol) tenham origem na imigração de comerciantes judeus-poloneses para essas respectivas regiões.

\subsection{A "Constituição polaca"}

Três dos principais dicionários do português brasileiro consultados (Aurélio, Michaelis e Houaiss) registram essa acepção, sempre acompanhada da rubrica "pejorativo". Ainda que se trate de uma constituição não mais vigente há muito tempo, nenhum dos dicionários inclui rubricas como "desusado" ou "obsoleto".

Em 1937, o presidente Getúlio Vargas deu um golpe de estado e instituiu o chamado Estado Novo no Brasil. Para referendar esse golpe, o então Ministro da Justiça Francisco Campos escreveu a "Constituição de 1937", que ficou popularmente conhecida como "Constituição Polaca". Segundo diversos autores (como Silva 2011: 229, e Porto 2012: 18), essa constituição recebeu a alcunha de Constituição Polaca porque teria sido modelada a partir da Constituição polonesa de 23 de abril de 1935 e, em especial, "continha elementos extremamente autoritários" (Silva 2011: 229). Como a unidade lexical polaca já tinha um sentido pejorativo na época (conforme já apresentado em 2.1), isso certamente trouxe um tom de crítica e de chacota a essa Constituição.

\subsection{Polaco como "pessoa loira e/ou de pele muito clara"}

O emprego de polaco para referir-se a pessoas loiras ou de pele clara é ainda corrente no português brasileiro, conforme podem atestar os próprios autores deste artigo e diversos outros falantes que foram consultados; no entanto, essa acepção não encontra registro em nenhum dos principais dicionários da língua portuguesa.

A motivação dessa acepção também é bem conhecida: como menos da metade da população brasileira é formada por pessoas brancas $(47,7 \%$ de brancos contra 52,3\% de outras etnias, 
segundo o censo demográfico de 2010 - IBGE, 2012), indivíduos de pele muito clara e cabelos loiros são pouco comuns (ainda que não raros) e são, frequentemente, associados a estrangeiros de origem europeia. Isso é refletido na linguagem: além de polaco, também são usadas as expressões galego e alemão para se referir esses mesmos indivíduos. No dicionário Houaiss (Houaiss; Villar, s/d), lê-se na oitava acepção do verbete galego: "indivíduo loiro ou ruivo" (com a rubrica "brasileirismo"); esse dicionário não registra a mesma acepção no verbete alemão, mas no dicionário Michaelis (2021 online), no verbete alemão, lê-se "Diz-se de indivíduo de pele clara e cabelo loiro" (acompanhado da rubrica "coloquial").

Como já mencionado, esses dicionários não registram essa acepção para polaco. O único dicionário que encontramos que menciona essa acepção é o Dicionário inFormal, que é na verdade um website que reúne definições de palavras da língua portuguesa escritas pelo público. No verbete polaco, encontram-se as definições "Loiro, galego" (inserção de número 2, incluída por um usuário em 2014), e "1. Pessoa do sexo masculino com pele clara e cabelos louros. feminino: polaca. (dialeto curitibano); 2. Galego (dialeto do estado de Santa Catarina)” (inserção de número 3, incluída por um usuário em 2009). Como se observa, são inserções recentes, indicando que essa acepção continua viva no português brasileiro. Ao mesmo tempo, também se observa que o Dicionário inFormal não registra a acepção de "prostituta" para polaca, confirmando a afirmação de que não se trata de uma acepção corrente na atualidade.

Ao contrário das duas primeiras acepções, que parecem ter origem na imigração de judeus-poloneses no Rio de Janeiro (conforme já mencionado), esta terceira acepção parece ter origem na imigração polonesa ocorrida a partir de fins do século XIX, especialmente no sul do Brasil (o que é corroborado pela percepção do usuário do Dicionário inFormal de que esse sentido é particularmente presente em Curitiba e em Santa Catarina, regiões que historicamente receberam muitos imigrantes poloneses). O que o Dicionário inFormal não menciona é que essa acepção frequentemente é sentida como pejorativa; ainda que nem sempre seja considerada uma ofensa, é muitas vezes empregada em tom de deboche ou chacota.

Esse sentido pejorativo pode estar relacionado a um fato histórico também muito documentado: a discriminação que as famílias de imigrantes poloneses sofreram (e, em certa medida, ainda sofrem) em certas regiões do sul do Brasil, em particular na região de Curitiba. As razões para essa discriminação já foram largamente estudadas em outros trabalhos (Oliveira 2015; Pereira 2017; Dantes 2019 são alguns dentre muitos) e variam desde a baixa qualificação dos primeiros imigrantes até o fato de que a Polônia, ao final do século XIX, estava sob o domínio de outras nações europeias. Tudo isso contribuiu para que a unidade lexical polaco ficasse estigmatizada, de modo que a própria comunidade de imigrantes preferiu adotar a designação de poloneses, considerada neutra.

\section{A recente revitalização da forma polaco como identidade de um povo}

Já no século XXI, com a maioria das acepções pejorativas em desuso, assiste-se a um movimento para a revitalização da unidade lexical polaco. A esse respeito, é muito conhecido o trabalho de Ulisses Iarochinski, ele próprio descendente de imigrantes poloneses, que, em artigo informal publicado online (Iarochinski, s/d), relata ter sido alvo de preconceitos, críticas e mesmo de agressão física ao lançar um livro intitulado "Saga dos Polacos - a história da Polônia e seus emigrantes 
no Brasil" (Iarochinski, 2000). Segundo ele, membros da própria comunidade de imigrantes e descendentes ainda têm muitas restrições quanto a serem chamados de "polacos" e, exatamente por isso, defende que a readoção de polaco por parte dessa comunidade deve ser estimulada como motivo de orgulho de suas próprias origens e como forma de combater o preconceito.

Entre seus argumentos, está o de que polaco é a tradução literal de polak, que é o gentílico usado na língua original do povo polonês e que, por isso, deve ser a forma preferida pela comunidade de imigrantes e descendentes; e que a adoção da forma polonês foi ocasionada por um preconceito que precisa ser combatido. Trata-se, portanto, de um argumento de ordem histórico-social, extralinguística.

Outro dos argumentos de Iarochinski (s/d) é o de que a forma polaco é empregada em outras línguas românicas, com exceção do francês, e a adoção de polonês teria ocorrido por "influência da cultura francesa, de uma elite preconceituosa" (nos dizeres de Anísio Oleksy, citado por Iachinski s/d: 17).

Conforme já mencionado na seção 2 deste artigo, tanto polaco quanto polonês têm longa tradição na língua portuguesa e têm correlatos em outras línguas românicas; no entanto, ainda que não se possa afirmar que polonês seja um decalque da forma francesa polonais, é importante observar que essa é a percepção de alguns falantes. É possível hipotetizar que a opção pela forma já existente polonês tenha ocorrido por ser essa a forma mais próxima da língua francesa, idioma que exerceu grande influência sobre o português brasileiro nas primeiras décadas do século XX.

Independentemente da discussão sobre qual das formas seria mais adequada (discussão essa que foge ao escopo deste artigo), é importante observar que a revitalização da forma polaco parece ser possível, no português brasileiro atual, porque, em primeiro lugar, o sentido pejorativo de "prostituta" já caiu em desuso há tempos; e, em segundo lugar, a sociedade brasileira vem obtendo importantes avanços no combate ao preconceito decorrente de raça e etnia.

Antes de passar às considerações finais, cabe mencionar que Iarochinski, em seu artigo, embora seja muito minucioso quanto aos dados referentes às prostitutas do século XIX, acaba por difundir uma história incorreta quanto à origem da acepção pejorativa. Ao abordar as origens do preconceito, afirma (Iarochinski s/d: 7):

O médico e pesquisador Edwino Donato Tempski prestou vários depoimentos em vida procurando explicar as origens do preconceito e a transformação do termo "Polaco" para uma palavra com sentido pejorativo e preconceituoso.

Segundo Tempski, a origem da utilização da palavra "Polaco", como termo depreciativo, teria tido início no começo do século XX, na cidade do Rio de Janeiro, quando o proprietário do Cassino da Urca trouxe prostitutas européias para trabalhar em seu estabelecimento de jogos. Como estas mulheres eram em sua maioria loiras como as "Polacas" do Sul do Brasil, a população começou a qualificá-las de "Polacas". Num momento imediatamente posterior, a população carioca passou a denominar qualquer prostituta, fosse loira, preta, branca, amarela ou índia com o termo "Polaca".

No Sul do Brasil, onde se concentrava a maior parte dos imigrantes e descendentes da etnia, a nova concepção do termo passou a ser utilizada como meio para agredir e menosprezar este grupo de pessoas.

Como já esclarecido na seção 2.1, essa história, ainda que possa ser verdadeira, não pode ser a origem da acepção pejorativa, porque já havia prostitutas de origem polonesa no Rio de Janeiro 
décadas antes da inauguração do Cassino da Urca (1933); o próprio Iarochinski mostra isso claramente, em seu texto. Além disso, conforme afirmamos, a primeira ocorrência dessa acepção data provavelmente de 1924 ("Vocabulário de Omissões" de Afonso d'Escragnolle Taunay), ou seja, data anterior ao Cassino. No entanto, essa história errônea acabou sendo reproduzida em outros trabalhos, como Martins (2009).

\section{Considerações finais}

No âmbito dos estudos do léxico, há um grande consenso de que os significados das unidades lexicais são reveladores da cultura do povo que as emprega. Em relação à unidade lexical polaco, suas diversas acepções revelam não só aspectos culturais, mas também aspectos da história social dos falantes do português brasileiro.

As formas polonês e polaco têm, ambas, uma longa tradição na língua portuguesa, tanto do Brasil quanto de Portugal. Ao contrário do que se possa pensar inicialmente, a forma polonês não deve ser considerada um brasileirismo, porque é criação da língua portuguesa do século XVII, como evidenciam os textos e dicionários consultados. Além disso, formas cognatas de polonês e polaco ocorrem na maioria das demais línguas românicas, com cada uma delas apresentando suas preferências (polaco em espanhol, polacco em italiano, por oposição a polonais em francês, polonès em catalão e polonez em romeno). A hipótese de que polonês seria um galicismo não pode ser comprovada, nem tampouco refutada, a partir dos dados de que dispomos atualmente.

A forma polaco, preferida em Portugal, adquiriu acepções pejorativas no Brasil, em decorrência de diversos fatos históricos. A primeira dessas acepções parece ter sido a de "prostituta, especialmente estrangeira", surgida a partir do tráfico de mulheres do Leste europeu, em geral judias, para trabalharem como prostitutas na cidade do Rio de Janeiro, ainda na segunda metade do século XIX.

A segunda acepção (a mais obscura delas, por estar documentada apenas por um autor, Arcy Tenório D’Albuquerque) é a de “comerciante, mascate”. Em princípio não é uma acepção pejorativa; no entanto, uma autoridade consular consultada por Almeida (conforme citado na introdução deste artigo) afirma que polaco designou "agentes de comércio ilícito", numa possível referência a essa acepção (contrabandistas?).

A terceira acepção é a alcunha da Constituição brasileira de 1937, que foi chamada de "Constituição polaca”, em princípio, por ter se inspirado na Constituição polonesa de 1935; mas certamente a alcunha já era sentida como pejorativa na época.

A quarta acepção, ainda empregada no Brasil, é a de "pessoa loira e/ou de pele muito clara". Não registrada em nenhum dos dicionários importantes do português brasileiro, ela surge do fato de que pessoas loiras ou de pele clara são pouco comuns no Brasil e, muito frequentemente, são descendentes de imigrantes europeus. Assim como polaco, também galego e alemão são empregadas para essa mesma acepção.

O fato de essa quarta acepção ser pejorativa é provavelmente decorrente do preconceito que imigrantes poloneses e seus descendentes sofreram (e, em certa medida, ainda sofrem) no Sul do Brasil, especialmente na região de Curitiba. Como iniciativa para combater esse preconceito, surge a iniciativa de se reapropriar da designação polaco como motivo de orgulho de um povo, o que ainda encontra resistência, que aos poucos vem sendo vencida. 
Com isso, é possível observar claramente de que forma o léxico reflete fatos sociais: as várias acepções da palavra polaco surgem e desaparecem à medida que ocorrem fatos históricos extralinguísticos. É possível propor a seguinte cronologia para descrever a história de polonês e polaco no português brasileiro (ainda que as datas apresentadas sejam uma aproximação muito vaga):

\begin{tabular}{|l|l|l|}
\hline \multicolumn{1}{|c|}{ Período histórico aproximado } & \multicolumn{1}{|c|}{$\begin{array}{c}\text { Emprego das formas polonês e } \\
\text { polaco }\end{array}$} & \multicolumn{1}{|c|}{ Fatos sociais } \\
\hline $\begin{array}{l}\text { Da criação (séculos XVI-XVII) } \\
\text { a meados do século XIX }\end{array}$ & $\begin{array}{l}\text { Emprego sinonímico de ambas as } \\
\text { formas, tanto no Brasil quanto em } \\
\text { Portugal }\end{array}$ & $\begin{array}{l}\text { Ausência de contato significativo } \\
\text { de falantes do português com } \\
\text { poloneses }\end{array}$ \\
\hline Aprox. 1870 até aprox. 1920 & $\begin{array}{l}\text { Início da estigmatização da forma } \\
\text { polaco no Brasil }\end{array}$ & $\begin{array}{l}\text { Início da presença de imigrantes } \\
\text { poloneses (comerciantes judeus, } \\
\text { prostitutas) }\end{array}$ \\
\hline Aprox. 1920 até aprox. 1950 & $\begin{array}{l}\text { Estigmatização da forma polaco } \\
\text { no Brasil (por significar "prostitu- } \\
\text { ta" ou outras acepções pejorativas) } \\
\text { e sua substituição por polonês }\end{array}$ & $\begin{array}{l}\text { Ocorrência de tráfico de mulhe- } \\
\text { res do Leste europeu; } \\
\text { Intensificação da imigração } \\
\text { polonesa e das colônias na região } \\
\text { Sul do Brasil }\end{array}$ \\
\hline Aprox. 1950 até aprox. 2000 & $\begin{array}{l}\text { Completa substituição de polaco } \\
\text { por polonês; } \\
\text { a forma polaco é rejeitada pela } \\
\text { comunidade de imigrantes e } \\
\text { descendentes; } \\
\text { desaparecimento da acepção } \\
\text { "prostituta" }\end{array}$ & $\begin{array}{l}\text { Presença mais intensa de polone- } \\
\text { ses e descendentes no país; } \\
\text { término do tráfico de mulheres } \\
\text { do Leste europeu }\end{array}$ \\
\hline Século XXI & $\begin{array}{l}\text { Redução da carga pejorativa de } \\
\text { polaco }\end{array}$ & $\begin{array}{l}\text { Desejo de se apropriar da } \\
\text { designação polaco por parte de } \\
\text { descendentes de poloneses }\end{array}$ \\
\hline
\end{tabular}

Com este artigo, esperamos ter contribuído com os estudos de Lexicologia do português no sentido de sistematizar as várias acepções de polaco e os motivos que levaram os falantes a substituí-lo por polonês; mas também no sentido de evidenciar as relações entre o léxico e a sociedade, mostrando de que forma os fatos histórico-sociais podem se refletir no léxico e na língua. 


\section{Referências bibliográficas}

Almeida, N. M. de (1981). Dicionário de questões vernáculas. São Paulo: Caminho Suave.

Amado, J. (2008). Jubiabá. São Paulo: Companhia das Letras. <https://www.terra.com.br/diversao/infograficos/jorge-amado-centenario/pdf/jubiaba.pdf > .

Aulete, F. C. (1958). Dicionário contemporâneo da língua portuguesa. Edição brasileira. Rio de Janeiro: Delta. Bandeira, M. de A. V. D. (2014). O Brasil na rota internacional do tráfico de mulheres: entre o início do século XX e a contemporaneidade. Dissertação (Mestrado em Relações Internacionais), Universidade de Brasília, Brasília. Disponível em: <https://core.ac.uk/download/pdf/33548685.pdf>.

Cabreyra, J. de (1636). Naufragio da Nao N. Senhora de Belem. Lisboa: por Lourenço Craesbeeck Impresso d'El Rey. <https://www.google.com.br/books/edition/Naufragio_da_N\%C3\%A0o_N_Senhora_de_Belem_fey/UvfpKuvaXUEC $>$.

Camões, L. de. (1990) Os Lusíadas. Introdução de Antônio Soares Amora. Belo Horizonte: ed. Itatiaia.

Costa, F. da S. (2015). Lima Barreto: O Brasil sob a ótica do Dr. Bogóloff. Dissertação (mestrado em Letras). UNESP, Campus de São José do Rio Preto. <https://repositorio.unesp.br/bitstream/handle/11449/138478/000864173.pdf>.

Cunha, A. G. da (1982). Dicionário etimológico Nova Fronteira da língua portuguesa. Rio de Janeiro: Nova Fronteira.

D’Albuquerque, A. T. (1942). Falsos brasileirismos. Argentinismos e americanismos erradamente apontados como brasileirismos. Rio de Janeiro: Editora Getúlio Costa.

- (1949). O nosso vocabulário. Estudos através da Semântica. Rio de Janeiro: Editora Getúlio Costa.

Dantes, Ch. (2019). Polonês ou polaco? As mudanças na percepção da Polônia no Brasil. Varsóvia. <https:// sistemas.mre.gov.br/kitweb/datafiles/Varsovia/pt-br/file/Disserta\%c3\%a7\%c3\%a3o_Karolina\%20Rudowska.pdf $>$.

Dexonline (s/d). Dicționare ale limbii române. Dexonline. Disponível em: <https://dexonline.ro/>.

Dicionário Informal. Disponível em: $<$ https://www.dicionarioinformal.com.br/>.

Ferreira, A. B. de H. (2010). Dicionário Aurélio da Língua Portuguesa. 5. ed. Curitiba: Positivo.

Ferreira Da Rosa, F. (1896). O Lupanar: estudo sobre o caftismo e a prostituição no Rio de Janeiro. Rio de Janeiro: [sem editora].

Figueiredo, A. C. de (1922). Novo dicionário da língua portuguesa. 3. ed. Lisboa: Ed. Portugal Brasil.

Houaiss, A.; \& Villar, M. de S. (s/d). Grande Dicionário Houaiss. Disponível em: https://houaiss.uol.com.br/.

Iarochinski, U. (s/d). Por quê polaco!. <https://pergamum.curitiba.pr.gov.br/vinculos/monogr/Texto/ Polaco.doc $>$.

- (2000). Saga dos Polacos - a história da Polônia e seus emigrantes no Brasil. Edição do autor.

IBGE (Instituto Brasileiro de Geografia e Estatística). (2012) Censo demográfico 2010. Características gerais da população, religião e pessoas com deficiência. Rio de Janeiro: IBGE. Disponível em: <https://biblioteca. ibge.gov.br/visualizacao/periodicos/94/cd_2010_religiao_deficiencia.pdf>.

Lima Barreto, A. H. de (1956). As aventuras do Dr. Bogóloff. In Os Bruzundangas (pp. 199-284). Brasiliense: São Paulo.

Machado, J. P. (1967). Dicionário etimológico da língua portuguesa. 2. ed. Lisboa: Editorial Confluência/Livros Horizonte.

Martins, A. A. (2009). A representação da identidade polaca no norte gaúcho. In Dermeval da Hora (org.) Anais do VI Congresso Internacional da Associação Brasileira de Linguística. João Pessoa: Ideia. 
<http://www.leffa.pro.br/tela4/Textos/Textos/Anais/ABRALIN_2009_vol_2/PDF-VOL2/Microsoft\%20 Word\%20-\%20Alessandra\%20Avila\%20Martins.pdf>.

Mascarenhas, J. F. M. (1717). A Águia Imperial Remontada no Orbe da Lua Ottomana. Lisboa Occidental: $\mathrm{Na}$ Officina de Pascoal da Sylva. <https://www.google.com.br/books/edition/A_aguia_imperial_Remontada_no_Orbe_da_Lu/hW9iAAAAcAAJ>.

Mello Moraes, A. J. de (1877). A Independencia e o Imperio do Brazil. Rio de Janeiro: Typ. do Globo. <https:// www.google.com.br/books/edition/A_independencia_e_o_imperio_do_Brazil_ou/mdU5AQAAMAAJ>.

Menezes, L. M. de (2017). Entre denúncias e propostas. O tráfico de brancas e os bastidores migratórios em obras de época. História (São Paulo), 36. <https:/www.scielo.br/pdf/his/v36/0101-9074-his-36-e108.pdf>.

Michaelis. (2021). Dicionário Brasileiro da Língua Portuguesa. São Paulo: Melhoramentos. https://michaelis. uol.com.br/moderno-portugues/.

Oliveira, M. de (2015). A inesperada descoberta de Otávio Ianni sobre preconceito contra descendentes de imigrantes poloneses em Curitiba. Sociedade e Estado, 30, 3. <https://www.scielo.br/scielo.php?script=sci_arttext\&pid=S0102-69922015000300799>.

Pereira, I. (2017). A voz de polono-brasileiros: um contexto histórico sul paranaense. Working Papers em Linguística UFSC 18 (1). <https://periodicos.ufsc.br/index.php/workingpapers/article/view/ 1984-8420.2017v18n1p23>.

Porto, W. C. (2012). 1937. Constituições brasileiras vol. IV. 3. ed. Brasília: Senado Federal, Subsecretaria de Edições Técnicas. <https://www2.senado.leg.br/bdsf/bitstream/handle/id/137571/Constituicoes_Brasileiras_v4_1937.pdf>.

Real Academia Española. (2020). Diccionario de la lengua española. Versión electrónica 23.4. <https://dle. rae.es/>.

Silva, J. C. J. (2011). Análise histórica das Constituições brasileiras. Ponto-e-vírgula, 10. <https://revistas. pucsp.br/index.php/pontoevirgula/article/view/13910>.

Taunay, A. d'E. (1924). Vocabulario de omissões. [Sem editora].

Treccani (s/d). Vocabolario. Istituto Giovanni Treccani. <https://www.treccani.it/vocabolario/>.

Trésor de la Langue Française Informatisé (1994). ATILF - CNRS \& Université de Lorraine. <http://atilf. atilf.fr/>. 
